\title{
Critical Thinking Dispositions of Undergraduate College Students in A Comprehensive University of Mainland China
}

\author{
Huarong $\mathrm{Ma}^{1}$ \\ ${ }^{1}$ School of Foreign Studies, Jiangnan University, Wuxi, People's Republic of China \\ Correspondence: Huarong Ma, School of Foreign Studies, Jiangnan University, Wuxi, People's Republic of China.
}

Received: August 17, 2021

Accepted: September 20, 2021

Online Published: September 24, 2021

doi:10.5430/ijhe.v10n6p224

URL: https://doi.org/10.5430/ijhe.v10n6p224

\begin{abstract}
This study was undertaken to assess the critical thinking dispositions of undergraduate college students in a comprehensive university of mainland China and examine the roles of gender and major in the subjects' critical thinking dispositions. An adapted Chinese version of the California Critical Thinking Dispositions Inventory (CCTDI) was used to survey 534 undergraduate students. Statistics revealed that over $3 / 4$ of the subjects were negative in their dispositions to think critically, and no more than 1/4 of them were positive. All the subscale mean scores were between 30-35, indicating an ambivalent attitude to critical thinking. Meanwhile, the subjects were stronger in systematicity, truth-seeking, and self-confidence than in analyticity, inquisitiveness, and cognitive maturity. Besides, males got significantly higher scores in overall critical thinking dispositions, truth-seeking, cognitive maturity, open-mindedness, and justice-orientedness, an added subscale in the Chinese version of CCTDI. Finally, science-engineering students achieved a non-significant higher overall mean score than non-science-engineering students. They also scored higher in seven out of the eight subscales, but the differences were only significant in open-mindedness and justice-orientedness.
\end{abstract}

Keywords: critical thinking dispositions, gender; major, mainland China

\section{Introduction}

Critical thinking is an important goal of higher education in this information age because students need effective cognitive strategies to process a tremendous amount of data to make decisions and take appropriate actions. Despite the consensus on the two dimensions - skills and dispositions- of critical thinking and on the importance of dispositions (Facione, 1990; Walsh \& Hardy, 1999; Giancarlo \& Facione, 2001; Facione \& Facione, 2013), the role of higher education in critical thinking dispositions (hereafter short-named as CT dispositions) has not been ascertained. While some studies (Giancarlo \& Facione, 2001; Lampert, 2007; Cisneros, 2009; Tüfekci, Küçükoğlu, Bölükbaş \& Tezel, 2011; Wen, 2012) concluded that higher education promoted the development of CT dispositions among college students, others (Liu \& Zhao, 2010; Ma, 2011) found that CT dispositions of undergraduate students did not improve with class levels.

Gender might be a challenge to critical thinking (Browne, Kubasek \& Harris, 1989) and a gender bias might exist in critical thinking (Wheary \& Ennis, 1995). Some studies (Halpern, 2003; Bagheri \& Ghanizadeh, 2016) stated that critical thinking was not a matter of gender, while others (Giancarlo \& Facione, 2001; Shubina \& Kulakli, 2019) concluded that gender has a significant influence on critical thinking. The inconsistent results call for further exploration.

Vygotsky's sociocultural theory emphasizes the important role of social interactions in the development of higher mental functions (Vygotsky, 1978). He believed that community played a central role in the process of making meaning. Since one of the centers of college students' social interactions is discipline-specific practices and activities, their CT dispositions might be related to their majors. Moreover, existing studies found that undergraduate pharmacy students (Cisneros, 2009), language majors (Wen \& Zhang, 2016), art students (Taskesen, 2019; Zhou, 2019) were positive in their CT dispositions, but bio-engineering students (Liu \& Zhao, 2010) were negative. Non-Asian nursing students were positive while Asian nursing students were negative in their CT dispositions (Salsali et al., 2013). This incomplete list of confronting results points to the need for further studies into the role of major in CT dispositions. 
In China, the education system has been driven by exams to a large extent (Yu \& Suen, 2005), and students have not had many opportunities to practice critical thinking (Dong, 2015). As a result, some scholars (Ge, Fu \& Hu, 2018) claimed that Chinese college students were weak in their critical thinking abilities.

Given the uncertain role of higher education in nurturing students' CT dispositions, the disputable relationship between gender and CT dispositions, the controversial effect of major on CT dispositions, and a possible lack of critical thinking in China's education, this cross-sectional study was undertaken to answer three questions: (1) What are the levels of overall CT dispositions and the subscales of undergraduate Chinese college students? (2) What are the dispositional differences in critical thinking related to gender among undergraduate Chinese college students? (3) What are the dispositional differences in critical thinking among undergraduate Chinese college students between science-engineering majors and non-science engineering majors?

\section{Literature Review}

\subsection{CT Dispositions and Inventories}

Critical thinking has two equally important dimensions: skills and dispositions (Facione, 1990). To assess CT dispositions, the California Critical Thinking Dispositions Inventory (CCTDI) (Facione \& Facione, 1992) was designed and validated (A. Facione, Giancarlo, C. Facione, \& Gainen, 1995) to measure the seven CT dispositional subscales: truth-seeking, open-mindedness, analyticity, systematicity, confidence in reasoning, inquisitiveness, and maturity of judgment. These subscales came from the consensus description of the ideal critical thinker:

"The ideal critical thinker is habitually inquisitive, well-informed, trustful of reason, open-minded, flexible, fair-minded in evaluation, honest in facing personal biases, prudent in making judgments, willing to reconsider, clear about issues, orderly in complex matters, diligent in seeking relevant information, reasonable in the selection of criteria, focused in inquiry, and persistent in seeking results which are as precise as the subject and the circumstances of inquiry permit" (Facione, 1990: 3).

The subscales are the different characterological traits of CT dispositions (Facione et al., 1995), thus studies into CT dispositions usually cover overall CT dispositions and the subscales.

This 75-item inventory does not involve discipline-specific knowledge and only assesses the subjects' feelings, attitudes, personality, and style, etc. It has been used by many studies (Walsh \& Hardy, 1999; Giancarlo \& Facione, 2001; Lampert, 2007; Cisneros, 2009; Wangensteen et al., 2010; Turan, 2016) to assess CT dispositions of students with different demographic and academic features.

CCTDI has been translated into different languages and used to measure CT dispositions of students in different countries. Three Chinese versions of CCTDI have been developed by a group of scholars (Luo \& Yang, 2001; Peng et al., 2004; Wen, Wang, Zhao, Liu \& Wang, 2011) and used in a Chinese context.

The following part reviews studies into CT dispositions that used different versions of CCTDI in different languages, with a focus on whether higher education can facilitate the nurturing of CT dispositions, the role of gender and major in CT dispositions. Besides, the review also draws a sketch of Vygotsky's sociocultural theory which will be used as the theoretical framework to help explain the results of this study.

\subsection{Higher Education and CT Dispositions}

On the positive side, higher education exerted a positive influence on college students' CT dispositions and the increase in overall CT dispositions was significant (Giancarlo \& Facione, 2001; Peng et al., 2004; Lampert, 2007; Shi, Jin \& Kong, 2009; Wangensteen et al., 2010; Tüfekci et al., 2011; Wen, 2012). On the negative side, higher education might have limited positive effect on students' CT dispositions (Luo \& Yang, 2001; Profetto-McGrath, 2003; Cisneros, 2009; Liu \& Zhao, 2010; Turan, 2016). CT dispositions even decreased when students moved from lower class levels to higher ones (Ma, 2011), but this might be explained away by their reluctance to choose extreme numbers in the questionnaire (Wen \& Zhang, 2016).

Next, college students' CT dispositions in the subscales were at different levels and were not developing in the same direction. Truth-seeking was often negative and got the lowest-rated mean score (Giancarlo \& Facione, 2001; Peng et al., 2004; Profetto-McGrath, 2003; Cisneros, 2009; Wangensteen et al., 2010; Wen, 2012; Zhou, 2019). The highest mean-score subscale differed from study to study, with inquisitiveness and systematicity often ranking in the first place.

Finally, students of upper-division standing scored significantly higher in truth-seeking (Giancarlo \& Facione, 2001; Lampert, 2007), CT self-confidence (Giancarlo \& Facione, 2001; Cisneros, 2009), systematicity (Profetto-McGrath, 2003; Lampert, 2007), and inquisitiveness (Lampert, 2007). However, a significant decrease was also seen in 
truth-seeking (Shi et al., 2009), open-mindedness (Cisneros, 2009; Shi et al., 2009), analyticity, and cognitive maturity (Shi et al., 2009). Besides, there were no significant differences in maturity, open-mindedness, analyticity, and self-confidence (Lampert, 2007), systematicity, self-confidence, and inquisitiveness (Shi et al., 2009).

From the above review, it can be seen that results of studies into CT dispositions, both overall and subscale scores, might be different based on where the studies were carried out and which version of CCTDI was used. With the limited number of similar studies conducted in China, it is necessary to conduct more studies into CT dispositions of Chinese college students to get a broader and deeper view of their CT dispositions.

\subsection{Gender and CT Dispositions}

Despite the non-correlation between gender and critical thinking asserted in some studies (Halpern, 2003; Bagheri \& Ghanizadah, 2016), more studies (Giancarlo \& Facione, 2001; Tüfekci et al., 2011; Shubina \& Kulakli, 2019) concluded that gender had a significant impact on critical thinking, including CT dispositions.

On the one hand, significant gender differences in overall CCTDI scores were found, with females scoring higher in some studies (Giancarlo \& Facione, 2001; Tüfekci et al., 2011). Females also scored significantly higher in open-mindedness (Giancarlo \& Facione, 2001; Shi et al., 2009), cognitive maturity (Giancarlo \& Facione, 2001; Shi et al., 2009), and inquisitiveness (Shi et al., 2009). Males reported significantly higher scores in analyticity (Wangensteen et al., 2010), and self-confidence (Shi et al., 2009). Conducted in different countries, such as the US, China, Turkey, and Norway, those studies produced diverse results, which indicates that CT dispositions of men and women might differ because of their cultural background.

On the other hand, although Walsh and Hardy (1999) found that females revealed non-significantly higher overall scores and females in both practice and nonpractice disciplines scored non-significantly higher in open-mindedness and maturity, they pointed out that CCTDI may not have successfully represented gender aspects of the dispositions toward critical thinking. This points to the need for conducting studies into CT dispositions of the two genders by using different versions of CCTDI or alternative inventories in other social contexts. Therefore, it is necessary to use a Chinese version of CCTDI to further explore the relationship between gender and CT dispositions in the context specified in this study.

\subsection{Major and CT Dispositions}

Vygotsky's sociocultural theory maintains that social interactions play a fundamental role in higher mental functions (Vygotsky, 1978). Discipline-related courses form an important basis for college students' social interactions, so it can be expected that CT dispositions of college students might differ based on their majors. Results of existing studies into the relationship between major and CT dispositions give some support to this argument.

Firstly, CT dispositions of some majors were positive, such as language majors (Peng et al.,2004; Wen \& Zhang, 2016), pharmacy students (Cisneros, 2009), science and engineering students (Zhou, 2019). Conversely, bio-engineering students and finance students were negative in their CT dispositions, although the former achieved higher overall scores than the latter (Liu \& Zhao, 2010). Besides, nursing students were positive (Peng et al., 2004; Wen \& Zhang, 2016) and negative (Tüfekci et al., 2011) in their overall CT dispositions.

Secondly, differences in subscale mean scores of CT dispositions were related to students' majors. There was a positive moderate relationship between art interest and analyticity, inquisitiveness; a significantly low positive relationship between art interest and self-confidence, systematicity, truth-seeking, cognitive maturity (Taskesen, 2019), but fine arts undergraduates scored significantly higher than non-arts undergraduates on truth-seeking, critical thinking maturity and open-mindedness (Lampert, 2007). Science students got significantly higher scores in truth-seeking than social science students, while the latter got higher scores in analyticity (Liu \& Zhao, 2010). Science undergraduates were also significantly better in inquisitiveness (Zhou, 2019).

Thirdly, the development of CT dispositions of different majors wasn't consistent over the process of higher education. Overall CT dispositions of some majors did not grow significantly, such as nursing students (Profetto-McGrath, 2003), teacher candidates (Turan, 2016), but Tüfekci et al., (2011) found CT dispositions were low among undergraduate and master nursing students and medium among doctoral nursing students and the differences were significant. Cognitive maturity went through positive changes, while systematicity went through obvious negative changes (Wen \& Zhang, 2016).

To summarize, based on existing studies, it is difficult to draw a clear picture about the relationship between CT dispositions and majors, which points to the need for more studies into dispositions of college students from different social and cultural backgrounds. 


\subsection{Theoretical Framework: Vygotsky's Sociocultural Theory}

Vygotsky's sociocultural theory about cognitive development will be used to help discuss the results of the present study. Therefore, some key ideas of the theory are shown in Fig. 1 below and a review is also given following Fig. 1.

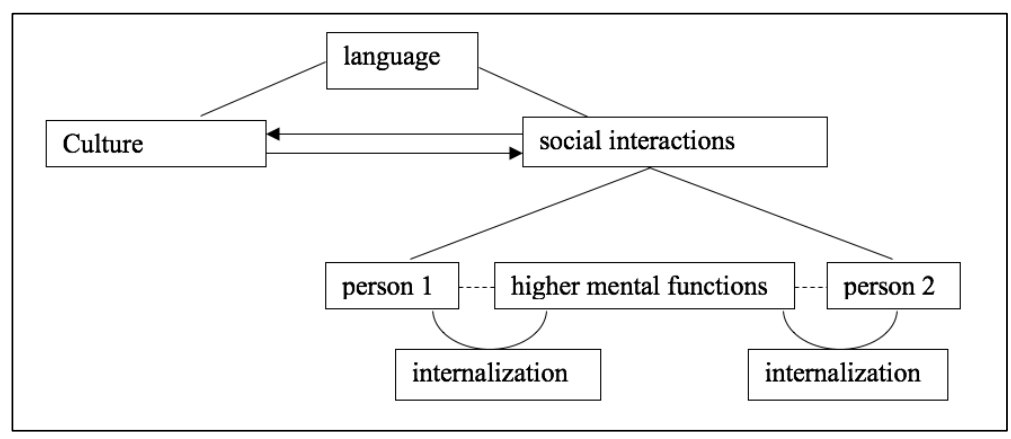

Figure 6. Vygotsky's sociocultural theory

Vygotsky (1978) believed that language and culture are significant in cognitive development. Attitudes, beliefs, conducts, ideas, etc., which help to form culture, are communicated through the use of language in social interactions. A complex relationship exists between culture and social interactions. Culture affects cognitive development because it influences social interactions, which in turn help to create culture.

According to Vygotsky (1978), the development of higher mental functions is mostly a social product, and involves an internalization process, which consists of a series of transformations. Of particular importance is the transformation from an interpersonal process into an intrapersonal one. "Every function in the child's cultural development appears twice: first, on the social level, and later, on the individual level; first, between people (inter-psychological) and then inside the child (intra-psychological). This applies equally to voluntary attention, logical memory, and the formation of concepts. All the higher functions originate as actual relationships between individuals" (Vygotsky, 1978: 57). Examples of higher mental functions include logical thinking, voluntary memory, and attention, etc.

Based on Vygotsky's theory described above, we can infer that critical thinking and the dispositions to think critically, being higher mental functions, might also be developed in social interactions and go through an internalization process.

\section{Methodology}

\subsection{Subjects}

The subjects were from a comprehensive university in China's Jiangsu province. The university, under the direct governance of the Ministry of Education of People's Republic of China, was ranked among the top 50 universities in China in 2020. A total of 534 freshmen $(109 ; 20.4 \%)$ and sophomores $(425 ; 79.6 \%)$ participated in this study, including 269 males and 265 females, 343 science-engineering students, and 191 non-science-engineering students, ranging from 18 to 22 in age. The subjects were convenience samples from 12 classes of Business English Reading and Writing course. The researcher of this study was teaching the 12 classes when data were collected in three semesters. The subjects were freshmen in their second semester and sophomores of different majors, including medicine, law, business, computer science, chemistry, etc. Though this is a comprehensive university, the majority of the students major in science and engineering. Therefore, it's difficult to find equal numbers of subjects from specific majors, say, language and business management, in convenience samples. As a result, the subjects were divided into science-engineering majors $(343 ; 64.2 \%)$ and non-science-engineering majors $(191 ; 35.8 \%)$. Besides, nearly $80 \%$ of the subjects had been in university for more than one year, although less than two years. It was not a very short time for higher education to exert some influence on their CT dispositions.

\subsection{Instruments}

This study used the CCTDI Chinese version, translated and adapted by Wen (2012) and her team members. It includes 50 test items, covering 8 subscales, among which seven are the same as those from CCTDI, and the eighth subscale is justice-orientedness, which measures subjects' attitude toward social injustice, violation of laws and immoral behaviours, etc. Each subscale includes 5-8 items and the items in the eight subscales are interspersed throughout the questionnaire. 
The reliability of the questionnaire was tested and the alpha value of the whole questionnaire reached .87 (Wen, 2012: 55). The validity of this questionnaire is not affected by the disciplines of students, so it can be used on college students of different majors (Wen, 2012: 56).

The instrument uses a 6-point Likert scale in which $1=$ strong agree and $6=$ strong disagree. According to Profetto-mcGrath (2003), with the seven-subscale inventory, the total scores range between 70 and 420, while subscale scores range from 10 to 60 . To calculate subscale scores, raw scores are multiplied by 10 and divided by the number of items in the subscale. The higher the score, the stronger the dispositions towards critical thinking are. Based on this, with the eight-subscale questionnaire, the total scores range between 80 and 480 .

Furthermore, the subjects' CT dispositions are divided into 4 groups: strong opposition towards CT, ambivalent attitude to CT, positive inclination, and strong dispositions (Wengensteen, Johansson, Bjorkstrom \& Nordstrom, 2010). The specific division and mean scores are summarized in Table 1.

Table 1. CT dispositions levels and scores

\begin{tabular}{llll}
\hline & total for 7 subscales & total for 8 subscales & individual subscale \\
\hline Strong dispositions & $>=350$ & $>=400$ & $>=50$ \\
Positive inclination & $>=280 \&<350$ & $>=320 \&<400$ & $>=40 \&<50$ \\
Ambivalence & $>210 \&<280$ & $>240 \&<320$ & $>30 \&<40$ \\
Strong opposition & $=<210$ & $=<240$ & $=<30$ \\
\hline
\end{tabular}

\subsection{Data Collection}

Data collection, conducted in three different semesters, namely March 2018, December 2018, and May 2019, occurred during regularly scheduled classes and the researcher herself was the teacher who was responsible for giving clear directions to the subjects. There were 4 different classes every semester. For the first time, a paper version questionnaire was handed out in class and students were given 15 minutes to read the directions and finish the questions. To solicit objective information, students were reminded that their answers to the questions would not have any effect on their scores in the Business Reading and Writing course. The announced purpose of the questionnaire to the subjects was to collect information on college students' ideas about some issues.

For the second and third time, the questionnaire was put online out of consideration of environmental protection, the easy availability of Wi-Fi and the wide use of smartphones. All other conditions were the same as the first time. The subjects scanned QR codes to access the questionnaire and finished it in class within 15 minutes.

\subsection{Data Analysis}

Data from the paper version questionnaire were put into an Excel file by the researcher herself. The online data were downloaded and checked by the researcher. All the data were put into SPSS (statistical package for social sciences-version 23) for analysis.

First, the reverse-coded items were changed into positive ones. Secondly, the scores were computed to get scores for each subscale and total scores. Thirdly, the reliability of the whole questionnaire and the subscales was analyzed by running the Cronbach's alpha in SPSS. Finally, independent samples T-test was run to analyze the influence of gender and major on CT dispositions.

\section{Results and Discussion}

\subsection{General Tendency and Subscales of CT Dispositions}

Table 2. overall mean scores of CT dispositions and their distribution

\begin{tabular}{|c|c|c|c|c|c|c|c|c|c|}
\hline & Mean & SD & Min. & Max. & $\begin{array}{l}\text { Strong } \\
(\mathrm{N} . / \%)\end{array}$ & $\begin{array}{l}\text { Ambivalent } \\
\text { (N./\%) }\end{array}$ & $\begin{array}{l}\text { Positive } \\
\text { (N./\%) }\end{array}$ & inclination & $\begin{array}{l}\text { Strong } \\
(\mathrm{N} . / \%)\end{array}$ \\
\hline $7 \mathrm{~S}$ & 228.20 & 56.47 & 99.76 & 375.70 & $236 / 44.2 \%$ & $181 / 33.9 \%$ & $104 / 19.5 \%$ & & $13 / 2.4 \%$ \\
\hline $8 \mathrm{~S}$ & 260.76 & 63.59 & 114.08 & 419.36 & $243 / 45.5 \%$ & $172 / 32.2 \%$ & $107 / 20 \%$ & & $12 / 2.2 \%$ \\
\hline
\end{tabular}

( $7 \mathrm{~S}=7$ subscales; $8 \mathrm{~S}=8$ subscales; the additional subscale is justice-orientedness) 
Table 3. subscale mean scores and ranks

\begin{tabular}{lllll}
\hline Subscales & Mean & Rank & Std. Deviation & Cronbach's alpha \\
\hline Analyticity & 30.59 & 8 & 11.63 & .885 \\
Inquisitiveness & 30.72 & 7 & 12.42 & .884 \\
Systematicity & 34.80 & 1 & 8.87 & .918 \\
Self-confidence & 33.88 & 3 & 8.13 & .903 \\
Truth-seeking & 33.91 & 2 & 7.96 & .903 \\
Cognitive maturity & 32.10 & 6 & 10.58 & .885 \\
Open-mindedness & 32.19 & 5 & 11.70 & .885 \\
Justice-orientedness & 32.55 & 4 & 9.33 & .894 \\
\hline
\end{tabular}

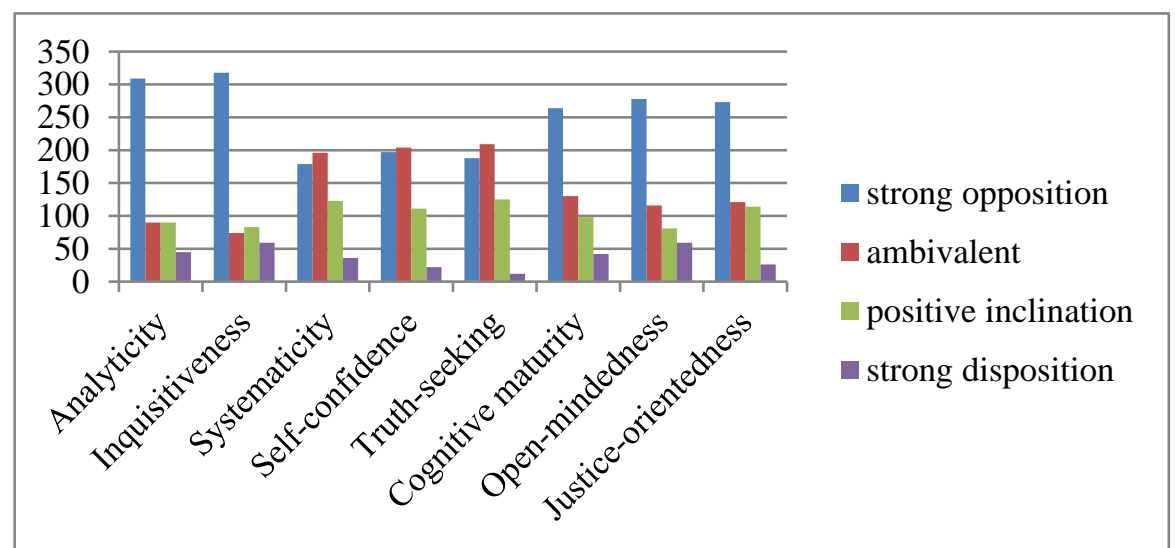

Figure 2. CT dispositions subscales and number of subjects falling into different levels

Over $3 / 4$ of the subjects were negative in their overall CT dispositions and no more than $1 / 4$ of them were positive in their CT dispositions. Compared with similar studies conducted in China, this result agreed with some studies (Luo \& Yang, 2001; Liu \& Zhao, 2010), but conflicted with other studies (Peng et al., 2004; Wen, 2012; Wen \& Zhang, 2016). The different findings between this study and Wen's study $(2012 ; 2016)$ were more interesting, because they used the same CT dispositions inventory. The mean score of CT dispositions measured by seven subscales in this study was lower than that of some studies in Canada and the US (Lampert, 2007; Cisneros, 2009; Wangensteen et al., 2010). However, the result was similar to that of Tüfekci et al.'s study (2011) which concluded that Turkish college students were mainly negative in their CT dispositions.-

For every subscale, the majority of the subjects were in the low score group and only a minority of them were in the high score group. The subjects scored highest in systematicity, which often ranked at the bottom of the list (Peng et al., 2004; Wen, 2012), but the mean score was still under 40. Inquisitiveness, which often topped the list (Profetto-McGrath, 2003; Wengensteen et al.,2010), ranked at the $7^{\text {th }}$ in this study. Truth-seeking, which often received the lowest score (Profetto-McGrath, 2003; Cisneros, 2009; Wengensteen et al., 2010), received the second-highest score in this study. The ranking of open-mindedness, self-confidence, and cognitive maturity did not vary very much from other studies.

Besides, the findings revealed that the subjects did not care very much about social justice. This was different from Wen's study (2012), which found that the subjects were positive in their justice-orientedness.

Vygotsky's (1978) sociocultural theory stresses the fundamental role of social interactions in the development of higher mental functions. Social interactions take place in particular cultures and social environments. Based on this theory, the subjects' negative dispositions in this study might be the results of several relevant factors.

Firstly, although critical thinking is not biased against particular cultures (Ennis, 1998), the uncritical cognitive orientation in Chinese cultural tradition has formed barriers to critical thinking education (Dong, 2015). For thousands of years the mainstream ideology in China emphasized social order, group thinking, and holistic 
perspective, which are not conducive to independent thinking, reasoning, and arguing, etc. some key elements of critical thinking.

Secondly, there is a lack of policy guidelines and emphasis on critical thinking from key educational policy documents issued by the Ministry of Education and the State Council, such as The Guidelines of Comprehensive Quality Improvement of Higher Education (2012), Implementation Guidelines for the Comprehensive Promotion for World-class Universities and World-class Disciplines (2015), The Thirteenth Five-year National Plan (2016-2020) for Education (2017). This lack of policy support might lead to the negligence of critical thinking ability in the curriculum design of schools and universities.

Thirdly, concerning critical thinking education, China is still in its infancy; its growing up has been difficult, and students don't have many opportunities to practice critical thinking (Dong, 2015). There is an exam-driven education in China and China's higher education has been driven by exams to a large extent (Yu \& Suen, 2005), but critical thinking has not been included in high-stake exams (Dong, 2015), such as the national college entrance exam, and national post-graduate entrance exam. Exams have washback effect, so the absence of critical thinking in the exams may make it more difficult to incorporate critical thinking into national curricula.

Besides, possible reasons should be given to explain the top rank of systematicity and truth-seeking and the bottom rank of inquisitiveness and analyticity.

On the one hand, emphasis on diligence and perseverance in the classic works from Qu Yuan, the patriot poet whose death is still commemorated in the form of the Dragon Boat Festival every year in China, to Confucian philosophy might have some positive impact on students' systematicity and truth-seeking, as shown in Chinese college students' strong belief that academic success is to be attained through effort $(\mathrm{Li}, 2002)$. This strong belief is part of personal epistemology which "has been found to be related to critical thinking performance, and more advanced development in epistemological understanding not only fosters thinking skills but also enhances the value for critical thinking" (Chan, Ho, \& Ku, 2011). Therefore, the strong belief that academic success is to be attained through effort may enhance their systematicity and truth-seeking.

On the other hand, repeated memorization, a typical feature in Chinese classrooms, might block the nurturing of inquisitiveness and analyticity, as Vygotsky stated that all high-level thinking skills occur in a social environment via social activities (Schunk, 2008).

\subsection{Gender and CT Dispositions}

Table 4. Gender and Mean Scores

\begin{tabular}{llrr}
\hline & \multicolumn{1}{c}{ Gender } & Mean & Std. Deviation \\
\hline Total score (7 subscales) & Male & 233.80 & 57.11 \\
Total score (8 subscales) & Female & 222.53 & 55.35 \\
& Male & 267.59 & 63.63 \\
Analyticity & Female & 253.83 & 62.91 \\
\multirow{3}{*}{ Inquisitiveness } & Male & 30.91 & 12.71 \\
\multirow{3}{*}{ Systematicity } & Female & 30.26 & 10.44 \\
& Male & 31.71 & 12.71 \\
Self-confidence & Female & 29.72 & 12.06 \\
\multirow{3}{*}{ Truth-seeking } & Male & 35.21 & 8.69 \\
Cognitive-maturity & Female & 34.39 & 9.06 \\
& Male & 33.95 & 8.42 \\
& Female & 33.81 & 7.85 \\
& Male & 34.74 & 7.75 \\
& Female & 33.08 & 8.10 \\
& Male & 33.37 & 10.36 \\
& Female & 30.82 & 10.66 \\
\hline
\end{tabular}




\begin{tabular}{lllr}
\hline Open-mindedness & Male & 33.91 & 11.26 \\
& Female & 30.44 & 11.91 \\
Justice-orientedness & Male & 33.79 & 8.94 \\
& Female & 31.30 & 9.57
\end{tabular}

Table 5. Independent Samples Test-Gender \& CT dispositions

\begin{tabular}{|c|c|c|c|c|c|c|c|}
\hline & $\begin{array}{l}\text { Levene's } \\
\text { Equality of }\end{array}$ & $\begin{array}{l}\text { for } \\
\text { iances }\end{array}$ & & & t-test for Equali & of Means & \\
\hline & $\mathrm{F}$ & Sig. & $\mathrm{t}$ & df & Sig. (2-tailed) & $\begin{array}{c}\text { Mean } \\
\text { Difference }\end{array}$ & $\begin{array}{l}\text { Std. Error } \\
\text { Difference }\end{array}$ \\
\hline 7 subscales & 1.22 & 0.27 & 2.32 & 532.00 & 0.02 & 11.27 & 4.87 \\
\hline 8 subscales & 0.61 & 0.44 & 2.51 & 532.00 & 0.01 & 13.75 & 5.48 \\
\hline Analyticity & 21.20 & 0.00 & 0.64 & 515.44 & 0.52 & 0.64 & 1.01 \\
\hline Inquisitiveness & 3.80 & 0.05 & 1.85 & 532.00 & 0.06 & 1.99 & 1.07 \\
\hline Systematicity & 0.53 & 0.47 & 1.07 & 532.00 & 0.29 & 0.82 & 0.77 \\
\hline Self-confidence & 0.86 & 0.36 & 0.19 & 532.00 & 0.85 & 0.13 & 0.70 \\
\hline Truth-seeking & 1.14 & 0.29 & 2.42 & 532.00 & 0.02 & 1.66 & 0.69 \\
\hline Cognitive-maturity & 0.21 & 0.65 & 2.81 & 532.00 & 0.01 & 2.56 & 0.91 \\
\hline Open-mindedness & 0.30 & 0.58 & 3.46 & 532.00 & 0.00 & 3.47 & 1.00 \\
\hline Justice-orientedness & 1.15 & 0.28 & 3.10 & 532.00 & 0.00 & 2.48 & 0.80 \\
\hline
\end{tabular}

Contrary to previous studies (Giancarlo \& Facione, 2001; Turan, 2016), this study found that males scored significantly higher than females in their total score of CT dispositions.

For subscales, no significant differences were found in analyticity, inquisitiveness, systematicity and self-confidence between male and female subjects, but males scored significantly higher in truth-seeking, cognitive maturity, open-mindedness, and justice-orientedness. Interestingly, some previous studies (Walsh \& Hardy, 1999; Giancarlo \& Facione, 2001; Shi et al., 2009) found that females scored significantly higher in open-mindedness, cognitive maturity, and inquisitiveness.

According to Vygotsky's (1978) theory of psychological development, certain social, educational and cultural factors might negatively impact CT dispositions of female subjects in this study.

Firstly, the difficulties in employment might discourage women from pursuing academic and career success which facilitates the nurturing of CT dispositions, as Vygotsky's claim that all higher mental functions originated in the social environment has a good degree of truth (Schunk, 2008). According to Catalyst (2020), China's economic reforms resulted in a variety of setbacks for women, including diminished employment opportunities, a widened gender wage gap, a lack of childcare and eldercare options, a resurgence of traditional stereotypes about women's work. Women's labor force participation has been declining since the 1990 s from $73.2 \%$ in 1990 to $60.5 \%$ in 2019 , while, in comparison, 75.3\% of men participated in the labor force in 2019. (Loo \& Thorpe, 2005) found that greater critical thinking ability would be associated with more liberal attitudes toward women's roles in society. The implication is that critical thinking ability and perceptions of women's roles in society might interact with each other. Therefore, the worsening employment and resurgence of traditional stereotypes about women's work might adversely influence the CT dispositions of female college students.

Secondly, students are often exposed to imbalanced gender representation in textbooks, with men outnumbering women; men enjoying more diverse jobs, higher social status, more school activities, etc; women being more connected with domestic roles, housework and fewer occupational roles (Wu \& Liu, 2015). Besides, film and TV programmes in China are replete with enduring and gendered discourses which lead women to internalize the rigid concepts of gender roles (Feldshuh, 2017). These gender stereotypes might negate open-mindedness, hinder the development of their cognitive maturity and inadvertently influence their willingness to explore thinking abilities, though we need empirical research to support this point. 
It is possible that the employment conditions and gender roles represented in textbooks, film, and TV programs might come into both men and women's language and their daily social interactions, which helps to reinforce gender stereotypes in the culture because according to Vygotsky (1978), language is a vital tool in cognitive development and social interactions.

Finally, cultural norms in many cultures, including Chinese culture, put more pressure on men to be successful and women to be supportive and submissive wives. One of the reasons for the difficulties in women's employment is traditional gender concepts (Gong, 2019) which try to confine women to domestic roles and limited occupational options. These norms might have rendered them less inclined to think critically because cultural conditioning affects an individual's thought and decision-making process (Ricci \& Su, 2013).

However, the non-significant differences in analyticity, inquisitiveness, systematicity, and self-confidence between males and females in this study prove that females are capable of critical thinking. The present era is different from previous ones. Time has taught females to be as good critical thinkers as males to overcome everyday difficulties, and to employ their critical thinking abilities despite their gender (Bagheri \& Ghanizadah, 2016). They just need a supportive social environment and cultural encouragement.

\subsection{Major and CT Dispositions}

Table 6. Major and Mean Scores

\begin{tabular}{llcrr}
\hline & \multicolumn{1}{c}{ Major } & Mean & Std. Deviation & Std. Error Mean \\
\hline 7 subscales & science-engineering & 229.89 & 56.05 & 3.03 \\
& non-science-engineering & 225.19 & 57.25 & 4.14 \\
8 subscales & science-engineering & 263.12 & 62.82 & 3.39 \\
& non-science-engineering & 256.53 & 64.90 & 4.70 \\
Analyticity & science-engineering & 30.83 & 12.19 & 0.66 \\
Inquisitiveness & non-science-engineering & 30.15 & 10.58 & 0.77 \\
& science-engineering & 31.05 & 12.56 & 0.68 \\
Systematicity & non-science-engineering & 30.13 & 12.16 & 0.88 \\
\multirow{5}{*}{ Self-confidence } & science-engineering & 34.49 & 8.69 & 0.47 \\
Truth-seeking & non-science-engineering & 35.37 & 9.19 & 0.66 \\
& science-engineering & 33.99 & 8.15 & 0.44 \\
Cognitive-maturity & non-science-engineering & 33.67 & 8.11 & 0.59 \\
& science-engineering & 34.12 & 7.90 & 0.43 \\
Open-mindedness & non-science-engineering & 33.56 & 8.07 & 0.58 \\
& science-engineering & 32.45 & 10.56 & 0.57 \\
Justice-orientedness & non-science-engineering & 31.49 & 10.61 & 0.77 \\
& science-engineering & 32.95 & 11.25 & 0.61 \\
& non-science-engineering & 30.81 & 12.39 & 0.90 \\
& science-engineering & 33.23 & 9.12 & 0.49 \\
& non-science-engineering & 31.34 & 9.62 & 0.70 \\
\hline
\end{tabular}


Table 7. Independent Samples Test-Major \& CT dispositions

\begin{tabular}{|c|c|c|c|c|c|c|c|}
\hline & $\begin{array}{r}\text { Leve } \\
\text { Equalit }\end{array}$ & $\begin{array}{l}\text { est for } \\
\text { ariances }\end{array}$ & & & st for Equalit & of Means & \\
\hline & $\mathrm{F}$ & Sig. & $\mathrm{t}$ & df & $\begin{array}{c}\text { Sig. } \\
\text { (2-tailed) }\end{array}$ & $\begin{array}{c}\text { Mean } \\
\text { Difference }\end{array}$ & $\begin{array}{l}\text { Std. Error } \\
\text { Difference }\end{array}$ \\
\hline 7 subscales & 0.00 & 0.96 & 0.92 & 532.00 & 0.36 & 4.71 & 5.10 \\
\hline 8 subscales & 0.08 & 0.78 & 1.15 & 532.00 & 0.25 & 6.59 & 5.74 \\
\hline Analyticity & 9.84 & 0.00 & 0.68 & 440.85 & 0.50 & 0.69 & 1.01 \\
\hline Inquisitiveness & 1.96 & 0.16 & 0.82 & 532.00 & 0.41 & 0.92 & 1.12 \\
\hline Systematicity & 1.56 & 0.21 & -1.10 & 532.00 & 0.27 & -0.88 & 0.80 \\
\hline Self-confidence & 0.22 & 0.64 & 0.44 & 532.00 & 0.66 & 0.32 & 0.73 \\
\hline Truth-seeking & 0.26 & 0.61 & 0.78 & 532.00 & 0.44 & 0.56 & 0.72 \\
\hline Cognitive-maturity & 0.06 & 0.81 & 1.00 & 532.00 & 0.32 & 0.95 & 0.96 \\
\hline Open-mindedness & 2.34 & 0.13 & 2.03 & 532.00 & 0.04 & 2.14 & 1.05 \\
\hline Justice-orientedness & 1.08 & 0.30 & 2.24 & 532.00 & 0.03 & 1.88 & 0.84 \\
\hline
\end{tabular}

There were no significant differences in the total scores of CT dispositions between science-engineering and non-science-engineering majors. Among the seven subscales in which science-engineering majors scored higher, differences were only significant in open-mindedness and justice-orientedness. Although non-science-engineering students scored higher in systematicity, the difference was not significant.

The findings supported previous studies (Walsh \& Hardy, 1999; Giancarlo \& Facione, 2001; Lampert, 2007; Liu \& Zhao, 2010; Wen, 2012; Taskesen, 2019), which claimed that differences were found in CT dispositions among college students of different majors. However, the most striking difference was the non-significant variance in the majority of subscales between the two discipline groups in this study.

Following Vygotsky's sociocultural theory, we can find that the factors leading to the non-significant variance might be sought from the subjects' shared learning experiences and their insufficient exposure to training in core courses of different disciplines.

Firstly, shared learning experiences might have contributed to the subjects' similarity in CT dispositions. The factors that influence critical thinking dispositions are mainly related to personal characteristics or experiences (Futami, Noguchi-Watanabe, Mikoshiba \& Yamamoto-Mitani, 2019). In China, there is a national curriculum in the educational system from primary school to high school, and some disciplines in higher educational institutions, such as college English and mathematics. At the pre-tertiary level, students use the same textbooks, and at the tertiary level, students use similar textbooks for non-specialized courses.

Secondly, demonstrable differences might exist between students of different academic disciplines in their critical thinking (Giancarlo \& Facione, 2001) because of the epistemological differences in the array of academic fields and between professional practice and traditional liberal arts programs (Schneider \& Shoenberg, 1998). However, this university only arranges some basic courses and elementary specialized courses for freshmen and sophomores. As a result, the subjects of this study, being in their first and second year, have not been exposed to enough core courses of their majors, which might be a reason for their lack of significant differences in their CT dispositions. This can also be supported by Vygotsky's idea that the development of higher mental functions is an internalization process, and "the transformation of an interpersonal process into an intrapersonal one is the result of a long series of developmental events" (Vygotsky, 1978: 57).

However, science-engineering students were more open-minded and more inclined to achieve social justice. The notion of critique is deemed as a core feature of science that should naturally challenge students' thinking (Osborne, 2014). Science-engineering students are more interested in and good at science early on in high school. Then, with the importance of humanistic qualities being emphasized by universities (Xu, Xing \& Chen, 2016), this university attaches great importance to the humanistic education of all students. As a result, the science-engineering students in this university are required to read some classic literary and social works, which exposes them to diverse modes of 
human experience. The exposure might be helpful to make them open to different views and more concerned about social justice.

Even so, this finding should be interpreted with caution. College students' attitude to social justice is related to many factors, such as university culture, family background, social status, and personal experience, etc. Besides, the majors were only divided into two categories, which made it impossible to tap into the finer differences in the subjects' subscales of CT dispositions.

\section{Conclusions}

Based on the data collected and findings summarized in this study, this paper tries to make the following tentative conclusions:

Firstly, the vast majority of the subjects were negative both in their overall CT dispositions and subscale dispositions. They were stronger in systematicity, truth-seeking, and self-confidence than analyticity, inquisitiveness, and cognitive maturity. The weak CT dispositions might be a result of uncritical cognitive orientation, lack of policy guidance, and the near-absence of critical thinking items in the exam-oriented educational environment.

Secondly, females were less inclined to think critically than males in this study. They scored significantly lower in the overall mean score of CT dispositions, truth-seeking, cognitive maturity, open-mindedness, and justice-orientedness. The weaker dispositions might result from an unsupportive social environment, especially declining employment for women, imbalanced gender representation and gender stereotypes in textbooks and media, and traditional cultural norms, etc.

Finally, science-engineering and non-science-engineering students did not differ significantly in their overall mean scores of CT dispositions and most of the mean scores of subscales, possibly because of their shared learning experiences and a lack of opportunities to practice critical thinking. Science-engineering students scored significantly higher only in open-mindedness and justice-orientedness, a possible outcome of the emphasis on critique in science learning and humanistic education in the university concerned. However, the findings here should be viewed with caution, as other factors might be involved.

Some implications could be drawn based on the findings and analysis of this study within the framework of Vygotsky's sociocultural theory of cognitive development:

Firstly, to nurture college students' CT dispositions, top-down efforts should be made given the situation in China. It is necessary for the Ministry of Education to incorporate critical thinking into key educational policies and high-stake examinations, such as college entrance examinations and graduate school entry examinations. Universities need to highlight the importance of critical thinking and "train instructors of critical thinking courses and subject-matter courses" (Dong, 2015). Teachers should be encouraged to adopt pedagogies that are conducive to cultivating CT dispositions, such as inquiry-based teaching and Socratic questioning. It is advisable to give students ample opportunities to engage in group projects, scenario-based exercises, peer teaching, etc. as Halpern (2003) asserted that critical thinking could be developed through gaining experiences and teaching them to others.

Secondly, to help nurture critical thinking skills and dispositions of women, it is necessary to improve employment for women, eliminate biased and stereotyped gender representation in textbooks and media, build cultural norms that are more supportive of career women. On the university level, teachers should bear no biased gender roles, because teachers can either reinforce gender stereotypes among students or help to eliminate gender bias and expand students' aspirations (USAID 2008, as cited in Wu \& Liu, 2015). Besides, teachers should handle the gender-biased contents, if there are any, in college textbooks in a way that can enlighten students about the nature of those gender biases.

Thirdly, to nurture CT dispositions of students from different disciplines, it might be helpful to incorporate critical thinking into basic courses and specialized courses, to establish departmental cultures which value inquiry-based critical pedagogy, because an inquiry-based curriculum, more heuristics, and critique-like discussions positively influence gains in critical thinking (Lampert, 2007). As a result, students of different majors might have equal access to a critical thinking environment.

To summarize, the implications focus on nurturing CT dispositions by creating a culture conducive to critical-thinking-enhancing social interactions, by giving students sufficient opportunities to practice their critical thinking to internalize this form of higher mental function. It may not only be applicable in China-but also countries with similar cultures.

The study is not without its limitations. It is a cross-sectional study, so it is not able to look at the changes in the subjects' CT dispositions. The sample of the study was not representative enough, because the subjects were 
freshmen and sophomores. Questionnaire items might be understood differently without real-life situations and the different scales might be rated differently, resulting in inconsistencies of choices among the subjects. The division of science-engineering students and non-science-engineering students is too vague to explore the complexity of CT dispositions among different majors.

The researcher of this study wants to give some recommendations for future studies. Firstly, longitudinal studies are needed to get more information about the development of CT dispositions in undergraduate college students throughout the four-year higher education. Besides, qualitative studies can be carried out to dig into the changes and complexity in college students' CT dispositions. Finally, future researchers in China can design and conduct researches to compare the scores of CT dispositions obtained from different inventories in Chinese so that necessary improvements can be made in the current CCTDI Chinese versions.

\section{Acknowledgements}

I would like to give my sincere thanks to my students in Jiangnan University who participated as subjects in the study. My special thanks also go to the Philosophy and Social Science Research Project administered by Jiangsu Provincial Department of Education in China.

\section{Funding}

This study was supported by the Philosophy and Social Science Research Project administered by Jiangsu Provincial Department of Education in China. It was sponsored under the project entitled "Serial Studies into Critical Thinking Dispositions of Chinese College Students and the Nurturing of Critical Thinking Dispositions" under Grant 2019SJA0778.

\section{References}

Bagheri, F., \& Ghanizadeh, A. (2016). Critical thinking and gender differences in academic self-regulation in higher education. Journal of Applied Linguistics and Language Research, 3(3), 133-145. https://www.researchgate.net/publication/327385027

Browne, M., Kubasek, N., \& Harris, J. (1989). The challenge to critical thinking posed by gender-related and learning styles research. To Improve the Academy, 168, 225-234. https://doi.org/10.1002/j.2334-4822.1989.tb00157.x

Catalyst, Quick Take: Women in the Workforce - China (April 14, 2020). https://www.catalyst.org/research/women-in-the-workforce-china/ accessed on April 16, 2021.

Chan, N. M., Ho, I. T., \& Ku, K. Y. (2011). Epistemic beliefs and critical thinking of Chinese students. Learning and Individual Differences, 21, 67-77. https://doi.org/10.1016/j.lindif.2010.11.001

Cisneros, R. M. (2009). Assessment of critical thinking in pharmacy students. American Journal of Pharmaceutical Education, 73(4), 1-7. https://doi.org/10.5688/aj730466

Dong, Y. (2015). Critical thinking education with Chinese characteristics. In: Davies M., Barnett R. (eds) The Palgrave Handbook of Critical Thinking in Higher Education. https://doi.org/10.1057/9781137378057_22

Ennis, R. H. (1998). Is Critical Thinking Culturally Biased? Teaching Philosophy, 21(1), 15-33. https://doi.org/10.5840/teachphil19982113

Facione, P. A. (1990). The Delphi Report-Critical Thinking: A statement of expert consensus for purposes of educational assessment and instruction. Newark: American Philosophical Association. Retrieved from ERIC Doc. No. ED 315-423.

Facione, P. A., \& Facione, N. C. (1992). The California Critical Thinking Dispositions Inventory. Millbrae, CA: The California Academic Press.

Facione, P. A., Giancarlo, C. A., Facione, N. C., \& Gainen, J. (1995). The dispositions toward critical thinking. Journal of General Education, 44(1), 1-25. https://doi.org/10.22329/11.v20i1.2254

Facione, P. A., \& Facione, N. C. (2013). Critical thinking for life: valuing, measuring, and training critical thinking in all its forms. Inquiry: Critical Thinking Across the Disciplines, 28(1), 5-25. https://doi.org/10.5840/inquiryct20132812

Feldshuh, H. (2017). Gender, media, and myth-making: constructing China's leftover women. Asian Journal of Communication. https://doi.org/10.1080/01292986.2017.1339721

Futami, A., Noguchi-Watanabe M., Mikoshiba N., \& Yamamoto-Mitani, N. (2019). Critical thinking dispositions 
among hospital nurses in Japan: Impact of organizational versus personal factors. Japan Journal of Nursing Science, e12298. https://doi.org/10.1111/jjns.12298

Ge, Qian, Fu, Hailun \& Hu, Mingtao. (2018). Re-consideration of the Cultivation of Chinese College Students' Critical Thinking. International Conference on Education, Psychology, and Management Science, UK: Francis Academic Press, 891-896. https://doi.org/10.25236/icepms.2018.191

Gong, Minyan. (2019). Why is it difficult for female college students to obtain employment in China?. International Journal of New Developments in Engineering and Society, 3(2), 18-27. https://doi.org/10.25236/IJNDES.19203

Giancarlo, C., \& Facione, P. (2001). A look across four years at the dispositions toward critical thinking among undergraduate students. The Journal of General Education, 50(1), 29-55. https://doi.org/10.1353/jge.2001.0004

Halpern, D. F. (2003). The "how" and "why" of critical thinking assessment. In Fasco, Jr. D. (ed) Critical Thinking and Reasoning: Current Research, Theory, and Practice. Cresskill, New Jersey: Hampton Press, Inc.

Lampert, N. (2007). Critical thinking dispositions as an outcome of undergraduate education. The Journal of General Education, 56(1), 17-33. https://doi.org/10.1353/jge.2007.0011

Li, J. (2002). A cultural model of learning: Chinese "heart and mind for wanting to learn". Journal of Cross-Cultural Psychology, 33(3), 248-269. https://doi.org/10.1177/0022022102033003003

Liu, Yi \& Zhao, Juming. (2010). The investigation of undergraduate students' critical thinking dispositions -Taking a local comprehensive university as an example. Research in Higher Education of Engineering, (1), 81-85.

Loo, Robert \& Thorpe, Karran. (2005). Relationships Between Critical Thinking and Attitudes Toward Women's Roles in Society, The Journal of Psychology, 139(1), 47-55. https://doi.org/10.3200/JRLP.139.1.47-55

Luo, Qingxu \& Yang, Xinhui. (2001). Revision for CCTDI (Chinese Version), Psychological Development and Education, (3), 47-51.

Ma, Yue. (2011). On the critical thinking dispositions of English majors. Journal of Guangdong University of Foreign Studies, 22(4), 92-95.

Osborne, J. (2014). Teaching critical thinking? New directions in science education. School Science Review, 352, $53-62$.

http://www.physics.smu.edu/ sdalley/quarknet/2015/2015QuarkNet_files/Physics\%20Curriculum\%20Construc ts/ASE\%20Teaching\%20Critical\%20Thinking\%20in\%20Science\%20Education.pdf

Profetto-McGrath, J. (2003). The relationship of critical thinking skills and critical thinking dispositions of baccalaureate nursing students. Journal of Advanced Nursing, 43(6), 569-577. https://doi.org/10.1046/j.1365-2648.2003.02755.x

Peng, Meici, Wang, Guocheng, Chen, Jile, Chen, Manhui, Bai, Hongmei, Li, Shouguo, Li, Jiping, Cai, Yunfang, Wang, Junqiao \& Yin, Lei. (2004). Validity and reliability of the Chinese critical chinking dispositions inventory. Chinese Journal of Nursing, 19(9), 644-697.

Ricci, Frederick \& Su, Angie. (2013). Cultural Conditioning: Influences on Critical Thinking. Journal of the Worldwide Forum on Education and Culture, 5(1), 47-54. https://nsuworks.nova.edu/fse_facarticles/289

Salsali, M., Tajvidi, M., \& Ghiyasvandian S. (2013). Critical Thinking Dispositions of Nursing Students in Asian and Non-Asian Countries: A Literature Review. Global Journal of Health Science, 5(6), 172-178. https://doi.org/10.5539/gjhs.v5n6p172

Schneider, C., \& Shoenberg, R. (1998). Contemporary Understandings of Liberal Education. Washington D.C.: Association of American Colleges and Universities.

Schunk, D. (2008). Learning Theories: An Educational Perspective. Upper Saddle River, NJ: Pearson Education.

Shi, Lichen, Jin, Lu \& Kong, Xiaowei. (2009). Investigation on the critical thinking dispositions of college students in Nanjing. China Journal of Health Psychology, 17(1), 13-15.

Shubina, I., \& Kulakli, A. (2019). Critical thinking, creativity and gender differences for knowledge generation in education. Literacy Information and Computer Education Journal, 10(1), 3086-3093. https://doi.org/10.20533/licej.2040.2589.2019.0405

Taskesen, Selma. (2019). A study on art interests and critical thinking dispositions of students in fine arts department of the faculty of education. International Journal of Educational Methodology, 5(1), 275-287. 
https://doi.org/10.12973/ijem.5.2.275

Tüfekci, F. G., Küçükoğlu, S., Bölükbaş, N., \& Tezel, A. (2011). Critical thinking dispositions of nursing students and influencing factors in Turkey. Journal of Society for Development in New Net Environment in $B \& H$, 5(4), 831-836. http://vedatisikhan.com/HealthMed.pdf\#page=136

Turan, Hakan. (2016). Comparison of critical thinking dispositions of prospective teachers. Educational Research and Reviews, 11(8), 867-876. https://academicjournals.org/journal/ERR/article-full-text-pdf/F4BB0BD58347.pdf

Vygotsky, L. S. (1978). Mind in Society: The Development of Higher Psychological Processes. Cambridge, MA: Harvard University Press.

Walsh, C., \& Hardy, R. (1999). Dispositional differences in critical thinking related to gender and academic major. Journal of Nursing Education, 38(4), 149-155. https://doi.org/10.3928/0148-4834-19990401-04

Wen, Qiufang, Wang, Jianqing, Zhao, Cairan, Liu, Yanping \& Wang, Haimei. (2011). Study of the reliability of critical thinking dispositions inventory for Chinese college students. Technology Enhanced Foreign Language Education, 142(6), 19-23.

Wen, Qiufang. (2012). Current Situation of Critical Thinking Abilities of Foreign Language Majors in China. Beijing: Foreign Language Teaching and Research Press.

Wen, Qiufang \& Zhang, Lingli. (2016). The development of critical thinking dispositions of foreign language majors: a longitudinal study. Technology Enhanced Foreign Language Education, 167(1), 3-8, 16.

Wengensteen, S., Johansson, I. S., Bjorkstrom, M. E., \& Nordstrom, G. (2010). Critical thinking dispositions among newly graduated nurses. Journal of Advanced Nursing, 66(10), 2170-2181. https://doi.org/10.1111/j.1365-2648.2010.05282.x

Wheary, J., \& Ennis R. (1995). Gender bias in critical thinking: continuing the dialogue. Educational Theory, 45(2), 213-224. https://doi.org/10.1111/j.1741-5446.1995.00213.x

Wu, Hong \& Liu, W. L. (2015). Gender Representation in Primary English Textbooks in Mainland China 1978 to 2003. International Journal of Humanities and Social Science, 5(6), 116-129. http://www.ijhssnet.com/journals/Vol_5_No_6_June_2015/15.pdf

Xu, Yanyang, Xing, Yue \& Chen, Sirui. (2016). An analysis of the current situation of science majors' humanistic qualities - taken Lanzhou University as an example. Gansu Science and Technology, 32(22), 74-76.

Yu, Lan \& Suen, Hoi K. (2005). Historical and contemporary exam-driven education fever in China. KEDI Journal of Educational Policy, $2(1), \quad$ 17-33. http://citeseerx.ist.psu.edu/viewdoc/download?doi=10.1.1.462.1285\&rep=rep1\&type=pdf

Zhou, Chaoying. (2019). Comparative research of critical thinking dispositions between undergraduates of arts and science. Academic Journal of Humanities \& Social Sciences, 2(5), 1-11. https://doi.org/10.25236/AJHSS.020501

\section{Copyrights}

Copyright for this article is retained by the author(s), with first publication rights granted to the journal.

This is an open-access article distributed under the terms and conditions of the Creative Commons Attribution license (http://creativecommons.org/licenses/by/4.0/). 